\title{
Questões metodológicas relacionadas com a análise de televisão
}

\author{
Arlindo Machado ${ }^{1}$ \\ PUC-SP \\ Marta Lucía Vélez ${ }^{2}$ \\ Universidad de Caldas, Manizales, Colômbia
}

\begin{abstract}
Resumo: Enquanto filmes e romances são unidades relativamente discretas, os programas de televisão são objetos muito mais diversificados, quando não mais complexos e, nesse sentido, mais difíceis de analisar. Nos anos 1970, Raymond Williams questionou o conceito "estático" $e$ "abstrato" de programa, considerando que em todos os sistemas de radiodifusão desenvolvidos o modo mais característico de organização é o da seqüência ou fluxo. Acrescente-se a isso ainda a dificuldade primeira de saber o que é um programa de televisão. Uma partida de futebol simplesmente transmitida ao vivo é um trabalho de televisão ou um "serviço" de distribuição? Para alguns, tudo o que vemos numa pequena tela eletrônica é televisão, mesmo quando feito fora dos estúdios de televisão. Para outros, mais radicais, tudo nas sociedades contemporâneas é feito para a televisão, inclusive as decisões políticas dos governos, as cerimônias oficiais e o terrorismo. Por fim, em toda análise televisiva há sempre uma diferença entre a metalinguagem (discurso verbal) e a linguagem objeto (programa de televisão), o que significa que um texto crítico jamais poderá dizer toda a verdade sobre seu objeto.
\end{abstract}

Palavras-chave: análise televisiva, programa televisivo, fluxo televisivo, gravação eletrônica de programas televisivos.

\begin{abstract}
While films and novels are relatively discrete singleness, television programs are subjects much more diversified, when not more complex, and, on that account, more difficult to analyse. In the seventies, Raymond Williams put in question the "static" and "abstract" concept of program, considering that in all developed broadcasting systems the characteristic organization is one of sequence or flow. Add to that the former difficulty to say what television is. A soccer game simply broadcasted live is a television work or a distribution "service"? For some, everything we see in a little electronic screen is television, even if made outside the television studios. For other, more radical, everything in contemporary societies is made for television, included political decisions by governments, authoritative cerimonies, and terrorism. At last, in all television analysis there is always a difference between the metalanguage (verbal discourse) and the objectlanguage (television program), what means that a critical text cannot always say every truth about its subject.
\end{abstract}

Key words: TV analysis, TV program, TV flow, video recording of TV programs.

1 Autor, entre outros, de O Sujeito na Tela (2007), Arte e Mídia (2007), A Televisão Levada a Sério (2000), Pré-cinemas \& Pós-cinemas (1997), Máquina e Imaginário (1196) e A Arte do Vídeo (1987).

2 Produtora e diretora de televisão, correspondente em Bogotá do canal parisiense France 2 e diretora de "La diferencia.co", instituição promotora de eventos relacionados com a mídia eletrônica na Colômbia. 
Em 1979, em seu livro L'analyse du film, Raymond Bellour propôs uma espécie de "sub-disciplina" dedicada a um estudo mais aprofundado, mais detalhado e mais rigoroso dos filmes enquanto entidades singulares, de modo a superar a mera descrição ou a mera opinião sobre um trabalho cinematográfico. Para Bellour, o avanço que as teorias do cinema já tinham conhecido, nos anos 1970, possibilitava uma aproximação mais minuciosa dos filmes, uma investigação metodologicamente mais severa e a superação do que até então se conhecia como crítica de cinema, de caráter impressionista e de precisão duvidosa. Da mesma forma como já estava em processo uma análise de textos literários (e, em escala menor, também de obras de artes plásticas), a "análise do filme" poderia se beneficiar das últimas conquistas da semiótica, dos estudos culturais, da psicanálise ou das ciências cognitivas para propor uma nova forma de abordar os filmes. Na época, Bellour considerava a “análise sintagmática” realizada por Christian Metz e Michèle Lacoste - publicada pela primeira vez em Image et Son, n. 201, janeiro de 1967, e depois republicada em Essais sur la signification au cinéma (1968) - do filme de Jacques Rozier Adieu Philippine (1962), “a primeira análise sistemática produzida sobre um filme observado na mesa de montagem, plano por plano, ou talvez segmento por segmento" (Bellour, 1979: 17).

Os tempos passaram, os exageros das abordagens estruturalistas foram devidamente equacionados e hoje já não se deposita mais tanta fé numa leitura "imanente" do texto, que acabou, em grande parte dos casos, desembocando num formalismo estéril e pouco útil para um exame amplo da importância de um trabalho para uma época ou para uma coletividade. Sem abdicar, todavia, do exame minucioso da realidade material da obra e sem deixar de prestar atenção à eloqüência maior ou menor com que ela mobiliza os recursos de linguagem do meio invocado, agora também são considerados o contexto em que uma obra é produzida e consumida, as molduras econômicas, ideológicas e psicológicas que norteiam a "leitura" que se faz delas e a amplitude maior ou menor do seu alcance. Se, nos tempos mais ortodoxos do estruturalismo, o que importava era o "texto" e apenas o "texto" (isto é, a obra na sua materialidade, o que nela está impresso em termos de imagem e som), hoje a análise de um trabalho audiovisual não descarta também os sub-textos relacionados a esse trabalho: as restrições (econômicas, políticas, institucionais, tecnológicas) 
impostas ao processo de realização, o diálogo do trabalho com o espaço e tempo de sua produção, a maneira como ele foi "lido" (aceito, rejeitado, criticado, interpretado) pelas diferentes parcelas do seu público e assim por diante. Alguns detalhes fundamentais para a análise de um programa de televisão, por exemplo, podem não estar dados no próprio "texto" do programa, mas precisam ser buscados em outros materiais (documentos de produção, textos jornalísticos relacionados ao trabalho, depoimentos da equipe produtora, análise de recepção, análise de conjuntura etc).

Ainda assim, este artigo sobre os problemas da análise do programa televisivo quer se inscrever, guardadas as devidas distâncias no tempo e no espaço, no mesmo espírito da abordagem proposta nos anos 1970 por Bellour, pelo menos no que diz respeito à busca de métodos mais precisos de análise de programas, que possibilitem resultados mais densos em termos de compreensão da real capacidade da televisão de dialogar com o mundo em que está inserida. Por razões diversas relacionadas com as estratégias das especialidades que buscaram entendê-la, a televisão produziu pouca reflexão analítica (pelo menos comparativamente, levando em consideração o que já se escreveu com relação a outros meios) sobre o modo como os seus produtos "comunicam" ou sobre como esses produtos "funcionam" tanto nas suas formas gerais relacionadas com formatos e gêneros, como nos detalhes mais íntimos que tornam cada programa um acontecimento singular. Na maioria das vezes, a abordagem da televisão é macroscópica e encara a televisão como uma estrutura abstrata de gerenciamento, financiamento, controle social, promoção do consumo e vinculação com o capital global, mas deixa de lado o exame efetivo do que ela concretamente produziu nos seus mais de 50 anos de história: os programas.

Claro que não é fácil analisar programas de televisão, se considerarmos a diversidade e a complexidade do objeto a ser analisado. Enquanto filmes e romances aparecem como unidades relativamente discretas, que podem ser tomadas como singularidades estáveis, passíveis de estudo individual, programas televisivos podem ser formas muito mais difíceis de caracterizar. Podemos definir o programa de televisão como qualquer série sintagmática (seqüência de imagens e sons eletrônicos) que possa ser tomada como uma singularidade distintiva em relação às outras séries sintagmáticas da televisão. Pode ser uma peça única, como um telefilme ou um 
especial; uma série ou minissérie apresentada em capítulos; um horário reservado para um gênero específico (seriado, telejornal, talk show etc), que se prolonga durante anos, sem previsão de finalização; ou até mesmo a programação inteira, no caso de emissoras ou redes "segmentadas" ou especializadas, que não apresentam variação de blocos. Mas essa definição não deixa de ter os seus problemas. No caso de uma série ou de um programa regularmente transmitido, pode ser que queiramos destacar o programa como um todo e pode ser também que queiramos destacar apenas uma ou outra edição particular (um episódio de um seriado ou uma matéria específica de um telejornal). É preciso, portanto, saber distinguir entre um programa e uma edição específica de programa. Um outro aspecto da produção televisiva difícil de encontrar uma conceituação adequada é o das criações mais breves, normalmente inseridas nos programas ou entre os programas, como os spots publicitários ou os videoclipes. Embora possam ser tomados como sintagmas individuais, esses produtos não são considerados "programas televisivos" no sentido próprio do termo. Nessa categoria podem ser incluídos também os trabalhos de natureza mais gráfica, ligados à "identidade" televisiva, como é o caso das vinhetas e aberturas de programas concebidas por Hans Donner para a Rede Globo brasileira (algumas muito inspiradas), ou das incríveis variações com a logomarca da MTV (Music Television), que aparecem ao longo de toda a programação da rede norte-americana e suas sucursais em todo o mundo.

É verdade que a noção de programa tem sido bastante questionada em alguns estudos de televisão. Razões não faltam para isso: a televisão costuma borrar os limites entre os programas, ou inserir um programa dentro do outro, a ponto de tornar difícil a distinção entre um programa "continente" e um programa "conteúdo". Além disso, os programas de televisão carregam a contradição de terem uma duração, de um lado, cada vez mais reduzida (spots publicitários, videoclipes, logos de identidade da rede televisiva) e, de outro, cada vez mais dilatada (seriados, telenovelas). Nos dois casos, o que chamamos de programa resulta numa entidade tão difícil de ser identificada quanto definida. Nos anos 1970, Raymond Williams (1979: 78-118) questionou o conceito "estático" de programa, por considerar que, na televisão, não existem unidades fechadas ou acabadas, que possam ser analisadas separadamente do resto da programação. Em lugar do conceito de programa, ele 
contrapôs o conceito mais "dinâmico" de fluxo televisivo, em que os limites entre um segmento e outro não eram mais considerados tão marcados como em outros meios. "Em todos os sistemas mais desenvolvidos de radiodifusão, a forma característica de organização e, conseqüentemente, a experiência mais marcante, é a seqüência ou fluxo. O fenômeno do fluxo planejado é, portanto, a marca talvez definidora da radiodifusão, seja como tecnologia, seja como forma cultural" (id.: 86). Por outro lado, em televisão, a recepção tende a ser cada vez mais fragmentada e heterogênea, em decorrência principalmente do efeito zapping, ou seja, do embaralhamento de todos os canais com o controle remoto. E quanto mais se amplia a opção de canais (abertos ou fechados, gratuitos ou pagos, comerciais ou públicos) mais o espectador "zapa" de um canal para outro e menor é a possibilidade de ele assistir a programas inteiros. "Agora, sob a ameaça permanente do controle remoto, já não se contam mais histórias completas, esfacelam-se as distinções de gênero e formato, não mais sobra sequer a distinção ontológica entre realidade e ficção" (Machado, 1993: 161).

Apesar disso tudo e mesmo que a singularidade do programa de televisão continue sendo questionada, investigações empíricas têm demonstrado que tanto a produção quanto a recepção televisiva continuam se baseando fortemente em núcleos de significação coerentes, como os formatos, os gêneros e os programas. Em outras palavras, formatos, gêneros e programas continuam sendo os modos mais estáveis de referência à televisão como fato cultural. A bem dizer a verdade, também no jornal existe uma justaposição seqüencial de matérias heterogêneas e também na literatura é possível encontrar leitores que lêem vários romances simultaneamente, mas em nenhum desses casos se perde a noção de obra ou de matéria jornalística nos seus sentidos singulares, onde se pode inclusive destacar alguns talentos individuais. Por essa razão, podemos nos perguntar - juntamente com Casetti e di Chio (1999: 292) se o fluxo televisivo é o resultado da afirmação de alguma essência "natural" da televisão ou tão somente de uma contingência histórica particular. É preciso considerar finalmente - e esse nos parece o ponto mais importante - que a idéia de programa leva ainda, sobre a idéia de fluxo, a vantagem de permitir uma abordagem seletiva e qualitativa. O conceito de fluxo empastela toda a produção televisiva num caldo homogêneo e amorfo, enquanto o de programa permite nitidamente distinguir diferenças ou perceber qualidades que despontam sobre o fundo da mesmice. 
Portanto, a abordagem da televisão como um acervo de trabalhos audiovisuais, ou como uma coleção de programas não necessariamente homogêneos, permite discutir esse meio a partir de uma perspectiva valorativa ou, se quiserem, qualitativa.

Outra dificuldade é delimitar o tipo de produto que deve merecer a atenção de nossa análise. Muitas vezes, a televisão é utilizada para exibir filmes que foram feitos originalmente para o cinema, ou para transmitir espetáculos musicais, concertos e partidas esportivas, não necessariamente concebidos para a tela pequena. Procuramos tomar o cuidado (mas sabemos que não é uma tarefa fácil, pois há limites difíceis de discernir) de nos concentrar apenas em trabalhos pensados especificamente para televisão e que levaram em consideração questões próprias do meio, de sua linguagem, de sua tecnologia, de sua economia e de suas condições de recepção. Nesse sentido, um filme como Il Mistero di Oberwald (1981), apesar de realizado nos estúdios da Radiotelevisione Italiana, com recursos tecnológicos específicos da televisão, toda a sua concepção envolve uma estética cinematográfica (mesmo que inovadora) e o seu objetivo final era mesmo a transferência para película fotoquímica, com vistas à exibição na sala escura do cinema. Por essa razão, o filme de Antonioni pode ser considerado mais cinema que televisão. Já o telefilme de Rossellini La Prise de Pouvoir par Louis XIV (1966), apesar de realizado com todos os recursos tecnológicos do cinema (o videotape era uma tecnologia ainda rudimentar naquela época), já levava em consideração um enquadramento, uma iluminação e um andamento adequados para as condições de recepção da televisão e, nesse sentido, ele pode ser considerado mais televisão que cinema.

Um problema complicado é, portanto, distinguir entre obras feitas para a televisão e obras feitas nos estúdios de televisão para difusão em outros circuitos de exibição, como é o caso de muitos trabalhos de vídeo-arte. De fato, alguns dos criadores da vídeo-arte trabalharam como artistas-residentes nos estúdios de emissoras ou redes de televisão - Nam June Paik na PBS norte-americana, Otto Piene na WDR alemã, George Snow no Channel Four britânico, Gianni Toti na RAI italiana, só para citar alguns casos - mas os trabalhos ali realizados não se destinavam à televisão e sim ao circuito mais sofisticado dos museus e galerias de arte. $\mathrm{Na}$ verdade, o que aconteceu com estes artistas do vídeo não é muito diferente 
do que aconteceu com os compositores Pierre Schaeffer e Karlheinz Stockhausen, que desenvolveram respectivamente as músicas concreta e eletrônica no interior de estúdios de rádio - na Radiodiffusion Française de Paris (Schaeffer) e na Nordwestdeutscher Rundfunk de Colônia (Stockhausen) -, mas os trabalhos realizados não se destinavam à difusão através do rádio e sim às gravações fonográficas e (paradoxalmente) às salas de concerto.

Por fim, há uma questão mais complicada, que diz respeito à transmissão na televisão de espetáculos que aconteceram fora dela . Em geral, os estudos de televisão costumam descartar partidas esportivas, óperas, peças de teatro, espetáculos de dança e concertos de música erudita ou popular simplesmente reportados ou transmitidos, preferindo depositar a sua atenção nos espetáculos pensados especificamente para a abordagem televisiva, como os célebres concertos de Herbert Von Karajan repensados para a televisão por Henri-Georges Clouzot, na década de 1960. Ainda assim, na prática, essa distinção não é tão fácil de sustentar. Há quem considere que tudo o é exibido na tela pequena doméstica pode ser considerado televisão e isso por duas razões principais. Primeiro porque não há realmente "transmissão" ou "reportagem" sem adaptação, adequação, enquadramento, "tradução" do acontecimento aos recursos retóricos da televisão. Uma partida de futebol diretamente assistida em um estádio esportivo não é a mesma coisa que uma partida acompanhada em casa, através da mediação da televisão. E mesmo um filme feito originalmente para o cinema costuma ser "adaptado" para a televisão, através do seu reenquadramento para adaptá-lo à moldura 4:3 do vídeo, remontagem para fazê-lo "caber" na duração do programa que o contém e cortes para a entrada dos breaks comerciais. Em segundo lugar, pode-se também desconfiar de que tudo o que hoje acontece, na verdade acontece para a televisão. De fato, esse meio se inseriu de tal forma na vida cotidiana que agora é quase impossível pensar os acontecimentos do mundo sem a sua presença. O cinema de Hollywood, por exemplo, hoje considera a televisão um mercado fundamental e complementar ao das salas de cinema; por essa razão, seus filmes agora levam em consideração um enquadramento e uma seqüencialidade adequados para a pequena tela doméstica, já prevendo inclusive os pontos de corte para os breaks comerciais. No futebol, a televisão impôs a mudança da bola de couro cru pela bola xadrez e as 
camisetas tradicionais por outras de motivos cromáticos mais adequados à definição da câmera eletrônica. Aliás, como demonstra Benjamin Rader em seu livro In Its Own Image (1984), a televisão mudou substancialmente a prática dos esportes, participando ela própria da organização e administração dos eventos, transformando competições em espetáculos audiovisuais, privilegiando o esporte profissional em detrimento do atletismo amador e convertendo atletas em astros do show business. Acontecimentos políticos, cerimônias oficiais e até mesmo atentados terroristas são concebidos, antes de tudo, como encenações para a televisão. Não basta, portanto, dizer que a televisão traduz os acontecimentos em espetáculo: os próprios acontecimentos são hoje encenados como espetáculos para a televisão. Os eventos, via de regra, não acontecem mais por conta própria; eles pressupõem a mediação da televisão e são forjados em função dessa mediação, quando não são produzidos diretamente pela empresa televisiva ou sob sua influência direta.

Sem negar nenhum desses argumentos, é preciso evitar entretanto que uma hipertrofia do papel da televisão possa dissolver as especificidades de sua intervenção expressiva e comunicativa. Mesmo que os filmes de Hollywood já considerem agora a sua funcionalidade na pequena tela doméstica, não faz muito sentido encarar os longa-metragens hollywoodianos como programas de televisão. E ainda que tudo - ou quase tudo - no mundo contemporâneo se organize em função da onipresença da televisão, um estudo sério sobre esse meio deve se concentrar, tanto quanto possível, nos produtos criados especificamente para ele, sob pena da discussão sobre televisão degenerar rapidamente - como tem acontecido com muita freqüência - numa discussão genérica sobre a sociedade atual. Na nossa maneira de ver as coisas, uma análise do programa televisivo - como "sub-disciplina" específica - deve buscar seus objetos justamente ali onde a televisão produz uma diferença qualitativa com relação aos outros meios.

Chegamos então a uma outra questão importante: os critérios utilizados para a seleção dos programas merecedores da nossa análise. Embora teoricamente qualquer programa de televisão possa ser objeto de análise, pela simples razão de que foi para o ar e, portanto, deve ter sido visto por um certo número de espectadores, constituindo, portanto, um fenômeno de comunicação, por uma questão de economia 
de energia nossa atenção analítica tende mais a se concentrar em algumas experiências específicas de programas. Em primeiro lugar, em nome de uma maior amplitude das análises, preocupamo-nos em selecionar diferentes modalidades de programas (documentários e reportagens, seriados de ficção, talk shows, comédias e sitcoms, telenovelas, revistas culturais e de variedades), buscando de cada uma delas um exemplo ao mesmo tempo representativo e diferenciado. Dessa forma, tendemos a trabalhar com diferentes modelos de análise para diferentes gêneros e formatos, buscando, tanto quanto possível, examinar a televisão em sua abrangência e diversidade. Em segundo lugar, preferimos, tanto quanto possível, selecionar para análise experiências de televisão que se destacaram do fluxo televisivo, seja pelo seu caráter inovador, seja pela maneira diferenciada com que o próprio meio (a televisão) é invocado, seja pela resposta problematizadora que dá a questões extra-televisuais (sociais, antropológicas, psicológicas, econômicas, históricas etc.). A ênfase, portanto, não pode estar apenas nos aspectos meramente técnicos ou metodológicos da análise (visualização plano por plano, análise das seqüências, estudo de gêneros e formatos etc.), mas na relevância dos programas enquanto contribuições singulares à televisão e à cultura contemporânea. Na verdade, preocupa-nos o fato de que uma parte significativa da produção de conhecimento no campo dos estudos de televisão se concentre apenas em torno de alguns objetos hegemônicos, sempre relacionados com o sucesso de público (quantitativamente medido em termos de rating) e que discussões mais qualitativas, vinculadas a experiências de televisão mais significativas e problematizadoras, costumam ser imediatamente descartadas e taxadas de elitistas.

Não se trata, entretanto, de propor receitas. Seria absolutamente descabido tomar os textos sobre televisão como modelos de análise de programas e aplicá-los esquematicamente a quaisquer outros programas da mesma espécie. Não existem métodos genéricos, que possam servir como modelos universais de análise para quaisquer produtos audiovisuais. O método de abordagem para cada programa não pode ser tomado como algo predeterminado por um modelo ou teoria, mas deve derivar do próprio trabalho examinado. Há sempre um (ou vários) método(s) de abordagem implícito(s) em cada programa. É preciso deixar que o produto audiovisual se revele para o analista com a força de seus próprios enunciados. É 
preciso ter humildade suficiente para experimentar esse produto em sua singularidade e diferença, em vez de descaracterizá-lo, enquadrando-o em categoriais genéricas que apenas servem para atestar a teoria, mas não para explicar o objeto. Por essa razão, os métodos de análise se aplicam apenas aos trabalhos examinados. Outros programas irão requerer métodos diferenciados de abordagem.

Ainda do ponto de vista metodológico, uma ferramenta imprescindível para a análise do programa televisivo é o vídeo. Embora o convívio regular com a televisão seja requisito imprescindível do analista de televisão, uma vez que os programas transmitidos - sejam eles ao vivo ou não - são distintos das gravações em termos de atualidade e envolvimento (a emoção de acompanhar uma partida esportiva reportada ao vivo não é a mesma que aquela experimentada diante do replay de uma partida pré-gravada), ainda assim, a gravação em vídeo traz uma ajuda preciosa à análise. Graças a ela, pode-se trabalhar longamente com o programa, revê-lo quantas vezes for preciso, parar a imagem, congelá-la, exibi-la em velocidades diferentes, separar um fragmento, compará-lo com outros do mesmo ou de outros programas e assim por diante. Isso é justamente o que estamos chamando de análise: a desmontagem e remontagem de um programa para conhecer o seu modo de funcionamento. Em grego antigo, análysis significava exatamente isso: separação, decomposição, desagregação do todo em suas partes constituintes, para efeito de conhecimento.

No mesmo livro acima citado, Bellour se recorda de que muitos críticos de cinema, no período anterior ao surgimento do vídeo-cassete, anotavam suas observações sobre os filmes lá mesmo no escuro da sala de exibição. Na época, a análise rigorosa dos filmes só podia ser convenientemente feita na mesa de montagem, único dispositivo existente até então que permitia congelar uma imagem, voltar para trás, rever várias vezes um mesmo trecho, exibir em câmera lenta ou acelerada, interromper a exibição para posterior continuação etc. Mas o acesso aos filmes (os rolos de película de $35 \mathrm{~mm}$ ) e aos equipamentos de projeção era então quase proibitivo ao analista, devido principalmente aos custos. Como havia essa dificuldade, era preciso rever várias vezes um mesmo filme (nas salas de cinema e desde que ele estivesse sendo exibido comercialmente) e depois apelar para a 
memória, anotando rapidamente tudo o que ainda estivesse na cabeça. Noël Burch, em seu livro Praxis du cinéma, fala da "falsa recordação de filmes" (1969: 35), ou seja, dos erros de descrição de cenas por falha de memória, fenômeno que, segundo ele, tem relação com a própria natureza da recepção cinematográfica. Ele mesmo se recorda de que fez uma descrição do filme de Robert Bresson Un Condamné à Mort s'est Échappé (Um Condenado à Morte Escapou/1956) que depois se revelou "absolutamente equivocada" (id.: 35), conforme ele mesmo reconheceu numa nota de rodapé a uma reedição do mesmo texto. Bellour refere-se a um erro célebre de André Bazin, quando este afirmou (em Jean Renoir; 1971: 112) que o filme indiano de Renoir The River (Rio Sagrado/ 1951) é constituído apenas de planos fixos: na verdade, o filme tem pelo menos duas dezenas de travelings, inclusive um longuíssimo sobre o rio, que é impossível de não perceber. E o próprio Bellour reconhece que cometeu um erro absurdo, quando comentava a seqüência do casamento no filme de Vincente Minnelli Brigadoon (Lenda dos Beijos Perdidos/ 1954), ocasião em que transformou dois planos fixos em "um admirável movimento de câmera que eu literalmente sonhei" (1979: 13). Esse é o problema de "escrever de memória”, com a ajuda de algumas notas tomadas rapidamente na sala escura ou logo depois da saída dela.

Na direção contrária da análise por recordação, a análise de filmes de que trata Bellour era feita prioritariamente com a observação dos filmes na mesa de montagem, mas também podia basear-se em outras fontes, como roteiros e descrições plano a plano feitas por outros. Ela se fundava, de qualquer maneira, naquilo que Bellour, em várias partes de seu livro, denomina l'arrêt sur l'image (a parada da imagem), "condição preliminar de toda e qualquer análise" (Bellour, 1979: 26). A observação do filme na mesa de montagem permitia ao analista, num certo sentido, se desprender do fluxo ininterrupto das imagens e escapar da fascinação do filme para um esforço de análise, como o leitor do livro pode parar a leitura para refletir, imaginar, ou mesmo voltar a uma parte já lida, reler novamente um parágrafo não perfeitamente compreendido, grifar uma parte e fazer uma anotação ao lado. A mesa de montagem dava ao estudioso do filme a mesma operacionalidade da leitura do livro. O surgimento do vídeo-cassete e a possibilidade que ele trazia de gravar e reproduzir um programa de televisão deram ao analista de 
televisão uma ferramenta de trabalho que o analista de filmes, no passado, jamais chegou a ter plenamente, pelo menos na mesma escala e pelos mesmos custos. $\mathrm{Na}$ verdade, o próprio analista de filmes também se beneficiou do surgimento do vídeo, apesar de cinema e vídeo - diferentemente de televisão e vídeo - serem meios muito diferentes em termos de textura de imagem, enquadramento, condições de recepção etc. Para se dar conta dessa "pequena virada epistemológica" (Bellour, 1989: 185) introduzida pelo vídeo, basta ver como a recepção de programas em vídeo-cassetes se parece cada vez mais com a leitura de um livro: a visualização passa a ser agora um ato solitário, o programa pode ser interrompido a qualquer momento, seja para repetir algum trecho, seja para continuar a "leitura" num outro momento, "pequenas perversões que fazem do espectador cada vez mais um leitor" (id.: 185). A imagem se oferece portanto como um "texto" para ser decifrado ou "lido" pelo analista e não mais como paisagem a ser contemplada.

Um problema particular da análise de qualquer produto audiovisual é a divergência dos meios de expressão: a metalinguagem (texto verbal) é diferente da linguagem objeto (filme ou programa de televisão). Como se pode escrever sobre um objeto de outra natureza? Em primeiro lugar, há o problema da citação: não há como incluir na análise, a título de citação, os trechos audiovisuais de que se está falando. Em certos momentos é preciso recorrer a processos mistos, todos eles limitados: fotos fixas (still frames), fragmentos do roteiro, eventualmente até partitura da trilha musical, como já se fez antes na crítica cinematográfica. A análise literária leva uma vantagem sobre a maioria das outras pelo fato dela se fazer com os mesmos signos das obras sobre as quais se debruça, uma vez que metalinguagem e linguagem-objeto são sistemas da mesma natureza, ou seja, verbais. Portanto, para citar um trecho da obra literária analisada basta abrir aspas e reproduzir o texto. Evidentemente, na análise de televisão não é possível abrir aspas para inserir o fragmento de programa que se está discutindo. A análise do programa de televisão tem a desvantagem, portanto, de não poder contar com o próprio discurso sobre o qual fala. Além disso, há também o problema da irredutibilidade de um sistema de expressão a outro: um programa de televisão, como qualquer outro produto audiovisual, não pode ser inteiramente traduzido para o discurso verbal: ele deixa sempre uma "sobra", que é aquela margem de especificidade que justamente o distingue da metalinguagem 
adotada. Por essa razão, é preciso que a análise se dê conta de que não é (nem poderia jamais ser) a explicação última de seu objeto. Mesmo quando eficiente, ela não pode almejar mais que o diagrama da obra analisada, algo assim como um mapa abstrato de seu funcionamento como produção de sentido.

Um lugar privilegiado onde a análise de televisão pode acontecer é na atividade de ensino. De fato, na sala de aula podemos ter o programa de televisão (linguagem-objeto) coexistindo com a análise oral (metalinguagem), ou seja, a obra audiovisual sendo exibida simultaneamente com o seu comentário analítico. Na sala de aula, há ainda as possibilidades, sempre presentes, de parar a imagem e voltar a qualquer ponto. É nesse momento que a análise verdadeiramente não é afastamento, não é dissecação ou assassinato do objeto. O objeto permanece ali, vivo, com a força de suas imagens e sons, eventualmente com a força de suas idéias, e o discurso analítico deve, num certo sentido, duelar com ele para fazer-se ouvir. Qualquer equívoco, qualquer escorregão - dos dois lados - é imediatamente flagrado, denunciado. Nesse sentido, a análise de programas pode servir como um guia para a atividade de ensino, visando não apenas os futuros profissionais e estudiosos da televisão, mas também os espectadores como um todo. Em todos os lugares, cresce cada vez mais a idéia de que, dado o papel fundante que a televisão ocupa no mundo contemporâneo, ela deve ser ensinada universalmente, desde os primeiros níveis de escolaridade até os níveis mais avançados de pós-graduação.

Claro que se pode ter outros discursos sobre a televisão. A hipermídia oferece hoje a possibilidade de fundir num único meio e num único suporte todos os outros meios; e ela o faz ainda de uma forma integrada, de modo que textos escritos e oralizados, imagens fixas e em movimento, sons musicais ou ruídos, gestos, toques e toda sorte de respostas corporais se combinam para constituir uma modalidade discursiva única e holística. A hipermídia nos coloca, portanto, o desafio de aprender a construir o pensamento e expressá-lo socialmente através de um conjunto integrado de meios, através de um discurso áudio-tátil-verbo-moto-visual, sem hierarquias e sem a hegemonia de um código sobre os demais. Certamente, ela representará a via mais eloqüente para a evolução futura da análise de televisão. A própria vídeo-arte pode ser vista como uma metalinguagem crítica da televisão. 
Pode-se mesmo dizer, como o faz Anne-Marie Duguet (1981: 86), que a perturbação dos signos visuais e sonoros da televisão, o retalhamento e a desmontagem impiedosa de seus programas, de seus fragmentos, ou até mesmo de seus ruídos naturais, constituem a matéria de boa parte das pesquisas plásticas em vídeo. Daí por que não seria exagero dizer que a televisão tem sido o objeto mais direto e mais freqüente de reflexão da vídeo-arte nos seus mais de quarenta anos de história. Bellour (1979: 29) nos faz ainda recordar, no final de sua introdução a L'analyse du film, que o programa da televisão francesa Cinéastes de Notre Temps, dirigido nos anos 1960 por Janine Bazin e André S. Labarthe, foi "o único exemplo significativo de um discurso sobre o cinema conduzido pelo próprio cinema". Deixando de lado o ato falho de Bellour (no exemplo citado, o discurso sobre o cinema é conduzido pela televisão e não pelo cinema), podemos pensar numa possibilidade, muito mais sistemática, de programas de televisão de tipo metalingüístico, que analisam outros programas de televisão. Alguns exemplos da espécie já existem. Entre tantos outros, podemos citar: a série Television (Grã-Bretanha, 1984, dirigida por Michael Beckmham e outros), a mais completa análise da televisão feita pela própria televisão; Paper Tiger Television (EUA, no ar pelo canal de acesso público de Nova York desde 1981, com direção de DeeDee Halleck, George Stoney e outros), programa ao vivo de análise sistemática não apenas da televisão, mas de toda a mídia norteamericana; e Blob (Itália, desde 1989, direção de Enrico Ghezzi e Marco Giusti), perfeito exemplo de metatelevisão, ou seja, uma televisão crítica sobre a própria televisão italiana.

Mas enquanto uma análise da televisão pela própria televisão (ou por outros meios audiovisuais) é ainda uma promessa que rascunha suas primeiras tentativas, o texto escrito pode cumprir provisoriamente essa função. É o que esperamos com nossas próprias análises de programas televisivos. Se o objetivo foi cumprido ou não, cabe ao leitor avaliar. Textos verbais, como programas de televisão, devem ser objetos permanentes de análise e crítica. 


\section{Referências Bibliográficas :}

Bazin, André (1971). Jean Renoir. Paris: Champ Libre.

Bellour, Raymond (1979). L'analyse du film. Paris: Albatros.

(1989). "De la nouveauté des nouvelles images". Comment vivre avec l'image (M.Mourier, org.). Paris: Presses Univ. de France.

Burch, Noël (1969). Praxis du cinéma. Paris: Gallimard.

Casetti, Francesco e Frederico di Chio (1999). Análisis de la Televisión. Barcelona:

Paidós.

Duguet, Anne-Marie (1981). Vidéo, la mémoire au poing. Paris: Hachette.

Machado, Arlindo (1993). Máquina e Imaginário: o Desafio das Poéticas Tecnológicas. São Paulo: EDUSP.

Metz, Christian (1968). Essais sur la signification au cinéma. Paris: Klincksieck.

Rader, Benjamin (1984). In Its Own Image. How Television Has Transformed Sports. New York: Free Press.

Williams, Raymond (1979). Television: Technology and Cultural Form. Glasgow: Fontana/Collins. 